Cláudio Ferreira

\title{
O JULgamento das CONTAS PÚblicas E O SISTEMA DE CONTROLE PARLAMENTAR DO GOVERNO NA CONSTITUIÇÃO BRASILEIRA DE 1988.
}

Dissertação apresentada à Banca Examinadora da Faculdade de Direito da Universidade de São Paulo, como exigência parcial para obtenção do título de Mestre em Direito do Estado, sob a orientação do Professor Elival da Silva Ramos.

Universidade de São Paulo

Faculdade de Direito

São Paulo 


\section{RESUMO}

No direito constitucional brasileiro, desde a primeira Constituição (1824), ainda sob o regime imperial, o Executivo é obrigado a prestar contas ao Legislativo, sobre as despesas públicas.

A primeira Constituição republicana (1891) criou o Tribunal de Contas, como instituição auxiliar do Congresso, com a tarefa de elaborar um parecer prévio sobre as contas prestadas pelo Presidente da República ao Congresso, que faria o julgamento final. A Constituição de 1988 manteve para o Tribunal de Contas e para o Congresso as mesmas atribuições.

O principal objetivo deste trabalho é examinar, no contexto do sistema de controle parlamentar de Governo instituído pela Constituição atual, os fundamentos pelos quais o Congresso pode aprovar ou rejeitar as contas do Executivo.

FERREIRA, Cláudio. O julgamento das contas públicas e o sistema de controle parlamentar do Governo na Constituição brasileira de 1988. Dissertação (Mestrado) apresentada na Faculdade de Direito da Universidade de São Paulo, 2011. 


\begin{abstract}
In the Brazilian constitutional law, since the first Constitution (1824), yet under the imperial regime, the Executive Branch is obliged to accounts for the Legislative Branch, about the public expenditures.

The first Republican Constitution (1891) has created the Court of Accounts, as an auxiliary institution to the Congress, whit task to elaboration a previous analysis of the accounts rendered by the Brazilians Republic's President to the Congress, who makes the final judgment. The Constitution of 1988 keeping to the Court of Accounts and to the Congress the same attributions.

The main objective of this work is examine, in the context of Govern parliamentary control system established by actual Constitution, the fundaments by which the Congress can approve or reject the Executive's counts.
\end{abstract}

FERREIRA, Cláudio. The public counts judgment and the Govern parliamentary control system on the 1988' Brazilians Constitution. Dissertation (Master's Degree) presented at the São Paulo University Law School, 2011. 


\section{ÍNDICE}

Nota prévia - Delimitação do tema .......................................................................... 9

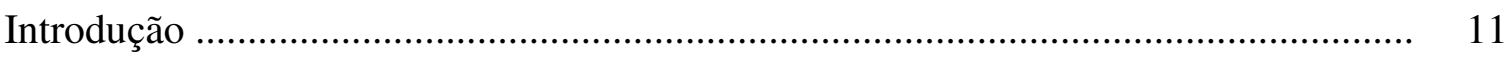

\section{PRIMEIRA PARTE: O controle do poder político}

Capítulo 1: O poder e o Estado ................................................................................. 13

Capítulo 2: O controle do poder político ……............................................................ 23

Seção 1: Evolução histórica ........................................................................ 23

Seção 2: O Parlamento e suas funções ............................................................. 35

Capítulo 3: O controle como poder e como função .................................................... 45

Capítulo 4: Controle e fiscalização ......................................................................... 49

Capítulo 5: O sistema de controle estabelecido pela Constituição de 1988 .................. 54

Seção 1: O controle sobre as atividades políticas ........................................... 56

Seção 2: O controle sobre as atividades financeiras ........................................ 58

\section{SEGUNDA PARTE: O orçamento}

Capítulo 6: O orçamento, sua origem e suas transformações ...................................... 60

Capítulo 7: O orçamento no Brasil .................................................................................. 63

Seção 1: Evolução histórica ....................................................................... 63

Seção 2: Configuração atual ..................................................................... 68

Capítulo 8: A natureza jurídica do orçamento ............................................................. 73

Capítulo 9: Princípio da legalidade, vinculação e discricionariedade ........................... 105

Seção 1: O orçamento como lei ..................................................................... 105

Seção 2: $\mathrm{O}$ orçamento como ato de administração ........................................... 112

TERCEIRA PARTE: O julgamento das contas públicas na Constituição de 1988

Capítulo 10: O orçamento e as contas públicas ......................................................... 119

Seção 1: O orçamento: ponto de convergência técnico-político-jurídico......... 119

Seção 2: A caracterização das contas públicas................................................ 123

Seção 3: Fundamentos do julgamento político................................................ 128

Capítulo 11: A posição do julgamento das contas no sistema de controle parlamentar do Governo estabelecido na Constituição de 1988 ..................................... 136

Capítulo 12: Conseqüências do julgamento ............................................................... 141

Capítulo 13: Panorama do julgamento das contas do Presidente da República .......... 149

Seção 1 - O período de 1964 a 1989 .............................................................. 150

Seção 2 - O período de 1990 a 2009 .............................................................. 151

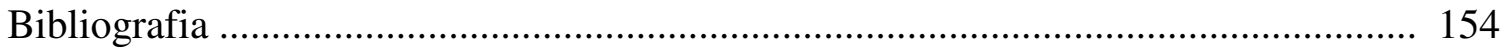




\section{NOTA PRÉVIA}

\section{Delimitação do tema}

O julgamento das contas públicas é a etapa final de um processo de controle que, por determinação constitucional (art. 70, parágrafo único), alcança “qualquer pessoa física ou jurídica, pública ou privada, que utilize, arrecade, guarde, gerencie ou administre dinheiros, bens e valores públicos ou pelos quais a União responda, ou que, em nome desta, assuma obrigações de natureza pecuniária".

O fenômeno contemporâneo do agigantamento do Estado trouxe consigo, entre outras consequiências, a multiplicação de órgãos e entidades encarregados da execução de uma quantidade cada vez maior de atribuições assumidas pelo Poder Público. Considerando-se que para o custeio dessas atividades são criadas novas receitas, resulta que quanto maior se torna o Estado, mais dinheiro público há para ser controlado. E mais pessoas são incluídas na abrangente descrição constitucional dos que estão obrigados a prestar contas.

Apesar desse aumento, há apenas duas instituições, genericamente consideradas, aptas a receber as prestações de contas e a julgá-las. São os Tribunais de Contas e os Poderes Legislativos, da União, dos Estados, do Distrito Federal e dos Municípios.

Os Tribunais de Contas foram introduzidos no Brasil pelo Decreto 966-A, de 07/11/1890, por obra do grande Rui Barbosa, então à frente do Ministério da Fazenda, para serem, segundo a exposição de motivos daquele decreto, um "corpo de magistratura intermediária à Administração e à legislatura, que, colocado em posição soberana, com atribuições de revisão e julgamento, cercado de garantias contra quaisquer ameaças, possa exercer as suas funções vitais no organismo constitucional”.

Desde seu nascimento, já receberia o Tribunal de Contas missão das mais relevantes, como elucidava seu mentor: "Convém levantar entre o poder que autoriza periodicamente a despesa e o poder que cotidianamente a executa um mediador independente, auxiliar de uma e de outra que, comunicando com a legislatura e intervindo na administração seja não só o vigia, como a mão forte da primeira sobre a segunda, obstando a perpetração das infrações orçamentárias, por um veto oportuno aos atos do executivo, que direta ou indireta, próxima ou remotamente, discrepem da linha rigorosa das leis de finanças".

A importância preconizada para esse órgão por Rui Barbosa foi sempre reconhecida, tanto que quatro meses depois de sua criação, quando da promulgação da 
Constituição de 1891, em 24 de fevereiro, o Tribunal de Contas foi contemplado em seu artigo 89, com a função de "liquidar as contas da receita e despesa e verificar a sua legalidade, antes de serem prestadas ao Congresso".

Desde então, o órgão responsável pela auditoria esteve presente em todas as Constituições brasileiras e ganhou nova dimensão com o crescimento do Estado, cumprindo papel capital no Estado de Direito.

Sobre as elevadas atribuições dos Tribunais de Contas há vasta literatura, sendo o tema tratado não apenas em obras específicas, mas constando de praticamente todos os manuais de Direito Financeiro, de Direito Tributário e de Direito Constitucional.

Apesar da incontestável relevância do trabalho dos Tribunais de Contas, não lhes compete, por expressa determinação constitucional, julgar as contas que anualmente devem prestar os Chefes do Poder Executivo (art. 84, XXIV), em nenhum nível, sendo essa missão reservada com exclusividade aos respectivos Poderes Legislativos (art. 49, IX).

Este trabalho restringir-se-á a procurar os fundamentos históricos, teóricos e constitucionais que impõem ao Chefe do Executivo a obrigação de prestar contas e que oferecem respaldo à prerrogativa do Legislativo de julgá-las, investigando a natureza de tais contas e analisando as conseqüências que desse julgamento podem advir.

Procurar-se-á situar o julgamento das contas no âmbito do controle parlamentar do Governo, para o que se buscará entender o sistema instituído pela Carta atual, considerando-se apenas as contas do Presidente da República e, por simetria, dos Governadores de Estado e do Distrito Federal e dos Prefeitos Municipais

Não se buscará precisar a eficácia do controle, uma vez que essa tarefa exigiria atenta investigação dos vetores político-partidários que orientam a relação entre os agentes públicos detentores temporários do poder, o que desbordaria dos limites propostos.

O regime democrático mostra que a convivência política é marcada pela existência de maiorias e minorias ocasionais, variando ao influxo dos interesses momentâneos. Essa volatilidade de interesses, porém, não é tanta que não permita a construção de um programa mínimo, em torno do qual se aglutinem, por um período mais ou menos duradouro, grupos ou facções que possuam interesses diversos.

Por isso, podem ocorrer períodos de predisposição para abrandamento do controle e períodos em que este é exercido de maneira mais rigorosa. Uma abordagem que visasse identificar a eficácia do controle ficaria vinculada a um determinado período, a uma determinada composição político-partidária, ou a ambos. E não poderia, como pretende este estudo, ter como referência as regras duradouras do Texto Constitucional. 


\section{INTRODUÇÃO}

O objetivo do trabalho é estudar o julgamento das contas públicas no contexto do modelo constitucional brasileiro de controle parlamentar do Governo.

O tema não tem despertado a atenção da doutrina.

Tal situação aumenta a dificuldade da pesquisa, assim como proporciona certa liberdade para a elaboração de um quadro teórico que acomode os diversos elementos cuja correlação compõe o cerne da investigação. Concorre para a complexidade do estudo o fato de sua estruturação exigir que se colham e se associem fragmentos de temas ligados ao universo de preocupações da Ciência Política, da Teoria do Estado, da Ciência da Administração, do Direito Administrativo, do Direito Financeiro e até do Direito Eleitoral.

Não obstante e mesmo sendo inevitável passear por outros domínios do saber, tais incursões serão limitadas ao mínimo indispensável, tanto em extensão quanto em profundidade, uma vez que o trabalho, quanto possível, limitar-se-á, no campo doutrinário, ao Direito Constitucional e, no âmbito do direito positivo, ao Texto Fundamental.

O que se buscará compreender, à luz do modelo positivado na Constituição, é a relação institucional entre o Executivo, que tem o dever de prestar contas, e o Legislativo, que tem o poder de julgá-las, investigando também o conteúdo das contas e os fundamentos desse julgamento.

Referências à legislação complementar ou ordinária, e mesmo à jurisprudência, acontecerão apenas quando houver relação essencial com o tema.

Na Primeira Parte, cuidar-se-á de situar o fenômeno do poder no âmbito do Estado, analisando a evolução de seu exercício e do esforço permanente para the impor limites. Seguindo uma linha de evolução histórica, serão mostrados os acontecimentos que resultaram na configuração política, social e econômica na qual surgiram os primeiros ensaios de controle do poder. Mostrar-se-á o surgimento do Parlamento e alguns momentos relevantes para seu fortalecimento, até sua ascensão definitiva, primeiramente com a Revolução Gloriosa e, depois, com a Revolução Francesa.

A seguir serão estudadas as principais funções do Parlamento, para tratar daquelas que mais diretamente interessam para o desenvolvimento do trabalho, a de controle e a de fiscalização, procurando compreender o conteúdo de cada uma. A Primeira Parte será concluída com a análise dessas funções no Texto Constitucional de 1988. 
Na Segunda Parte será estudado o orçamento, visando estabelecer sua natureza instrumental no exercício do poder político. De sua origem e evolução histórica, passar-seá para o panorama institucional pátrio, apresentando uma retrospectiva do orçamento no Brasil, que oferecerá elementos para evidenciar a nova formatação que lhe foi dada pela Carta de 1988.

A seguir, abordar-se-á a questão da natureza jurídica do orçamento, que é razão de muitas divergências doutrinárias, mas que se reveste de importância fundamental para o desenvolvimento do trabalho. Partindo da exposição das concepções clássicas, analisar-seá a configuração dada ao instituto pela Constituição de 1988, mostrando a participação reservada ao Parlamento no processo de planejamento orçamentário.

A Segunda Parte será concluída com uma análise do dimensionamento da vinculação e da discricionariedade no âmbito dos orçamentos, por serem eles elementos indispensáveis para aferição da obediência ao princípio da legalidade pelo Poder Público.

Na Terceira Parte será investigada a caracterização das contas públicas, tendo como ponto de partida sua vinculação com o orçamento. A análise se desenvolverá com a investigação dos fundamentos do julgamento político a cargo do Legislativo.

Em seguida, proceder-se-á à localização do julgamento das contas na estrutura teórica, histórica e constitucional resultante da junção dos diversos elementos estudados o Governo, o Parlamento, o controle do poder político, o orçamento, as contas - e se analisará as conseqüências do julgamento. 


\section{BIBLIOGRAFIA}

ALMEIDA, Fernanda Dias Menezes de. Competências na Constituição de 1988. São Paulo: Atlas, 1991.

AMARAL, Getúlio Sérgio do. Direito à defesa do Prefeito nos julgamentos das contas municipais. Belo Horizonte: Inédita, 2000.

APOSTOLIDÈS, Jean Marie. O rei-máquina: espetáculo e política no tempo de Luis XIV. Trad. Claudio Cesar Santoro. Rio de Janeiro: José Olympio; Brasília: Edunb, 1993.

ARISTÓTELES. A Política. Trad. Nestor Silveira Chaves. Rio de Janeiro: Edições de Ouro, 1960.

BALEEIRO, Aliomar. Uma introdução à Ciência das Finanças. $15^{\mathrm{a}}$ ed. Revista e atualizada por Dejalma de Campos. Rio de Janeiro: Editora Forense: 2001.

BARBOSA, Rui. Relatório do Ministro da Fazenda Rui Barbosa, em janeiro de 1891, Rio de Janeiro: Imprensa Nacional, 1891.

BASTOS, Celso Ribeiro. Curso de Direito Financeiro e Tributário. $9^{\text {a }}$ ed., atualizada e ampliada. São Paulo: Celso Bastos Editor, 2002.

. Curso de Teoria do Estado e Ciência Política, $4^{\mathrm{a}}$ ed., São Paulo: Editora Saraiva, 1999.

e MARTINS, Ives Gandra. Comentários à Constituição do Brasil. São Paulo: Editora Saraiva, 1989. v. 2; 1991. v. 6, Tomo II; 1990. v. 7;

BLOCH, Marc. Reis Taumaturgos: o caráter sobrenatural do poder régio. França e Inglaterra. $2^{\mathrm{a}}$ Reimpressão, Prefácio de Jacques Le Goff. Tradução: Júlia Mainard. São Paulo: Cia. das Letras, 1999.

BOBBIO, Norberto. Teoria Geral da Política: a filosofia política e as lições dos clássicos, $11^{\text {a }}$ tiragem, tradução Daniela Beccaccia Versiani. Rio de Janeiro: Elsevier Editora Ltda., 2005.

. Studi per uma Teoria Generali del Diritto. Torino: Giappichelli Editore, 1970.

Teoria do ordenamento jurídico. $9^{\mathrm{a}}$ ed., tradução de Maria Celeste C. J. Santos. Brasília: Editora Universidade de Brasília, 1997.

BODIN, Jean. Les Six Livres de la Republique. Fayard, Paris, 1986 - reimpressão, com manutenção da ortografia original, da Edição de Lyon,1593 por Gabriel Cartier. 
BONAVIDES, Paulo. Ciência Política. 11 a ed., São Paulo: Malheiros Editores, 2005.

BOSSUET, Jacques-Bénigne. Política Tirada da Sagrada Escritura. In: FREITAS, Gustavo de. 900 Textos e Documentos de História, s/d. Lisboa: Plátano Editorial.

BÖCKENFÖRDE, E.W., La páce di Westphalia e il diritto d'aleanza dei ceti dell'Impero”, em E. Rotelli e P. Schiera (orgs.), Lo stato moderno. Bolonha, 1974, v. 3.

BUCCI, Maria Paula Dallari. Direito administrativo e políticas públicas. São Paulo: Editora Saraiva, 2002.

CAGGIANO, Monica Herman Salem. Direito parlamentar e eleitoral, Barueri: Manole, 2004.

CALDWELL, Peter. Popular sovereignty and the crisis of German Constitutional Law. Durham: Duke University Press, 1997.

CAMPOS, Dejalma de. Direito Financeiro e Orçamentário. $2^{\mathrm{a}}$ ed., São Paulo: Editora Atlas, 2001.

CAMPOS, Francisco. Parecer. In: Revista de Direito Administrativo, vol. 71, jan/mar, 1963.

CÂNDIDO, Joel José. Direito Eleitoral Brasileiro. 11 a ed. Bauru: Edipro, 2004.

CANOTILHO, J. J. Gomes. A Lei do Orçamento na Teoria da Lei. Separata do número especial do Boletim da Faculdade de Direito de Coimbra: Estudos em Homenagem ao Prof. Doutor José Joaquim Teixeira Ribeiro. Coimbra: 1979.

CARVAlHO, Paulo de Barros. Curso de direito tributário, $15^{\mathrm{a}}$ ed. rev. atual., Editora Saraiva, São Paulo: 2003.

CASTRO, José Nilo de. Julgamento das Contas Municipais. $3^{\text {a }}$ ed. rev., ampl., atual. Belo Horizonte: Editora Del Rey, 2003.

CHAUÍ, Marilena. Brasil: mito fundador e sociedade autoritária. São Paulo: Fundação Perseu Abramo. 2000. Convite à Filosofia. São Paulo: Ática, 2000

CHEVALLIER, Jean-Jacques. As grandes obras políticas de Maquiavel a nossos dias. Rio de Janeiro: Agir, 1957. 
COMPARATO, Fábio Konder. O poder de controle na sociedade anônima. $2^{\mathrm{a}}$ ed. atualizada. São Paulo: Editora Revista dos Tribunais, 1977.

COSTA, Tito. Responsabilidade de Prefeitos e Vereadores. $4^{\mathrm{a}}$ ed. São Paulo: Editora Revista dos Tribunais, 2002.

. Recursos em Matéria Eleitoral. $8^{\mathrm{a}}$ ed. São Paulo: Editora Revista dos Tribunais, 2004.

CRETELla JÚNIOR, José. Comentários à Constituição de 1988. Rio de Janeiro: Editora Forense, 1989, v. 1; 1989. v. 2.

DALlARI, Adilson Abreu. Constituição e orçamento, Cadernos de Direito Constitucional e Ciência Política, 15, São Paulo: Revista dos Tribunais, 1996.

Lei orçamentária - processo legislativo - peculiaridades e decorrências. In: Cadernos de Direito Constitucional e Ciência Política, São Paulo: RT, ano 5, n 19, abr/jun 1997.

DALLARI, Dalmo de Abreu. Elementos de teoria geral do estado. $21^{\text {a }}$ ed. São Paulo: Editora Saraiva, 2000.

DINIZ, Maria Helena. Lei de introdução ao código civil interpretada, $9^{\mathrm{a}}$ ed. Editora Saraiva, São Paulo: 2002.

DI PIETRO, Maria Sylvia Zanella. Direito Administrativo. $18^{\text {a }}$ ed. São Paulo: Editora Atlas, 2005. Discricionariedade administrativa na Constituição de 1988. $2^{\mathrm{a}}$ ed. São Paulo: Editora Atlas, 2001.

DI RUFFIA, Paolo Biscaretti. Direito Constitucional e Instituições de Direito Público, tradução de Maria Helena Diniz, São Paulo: Editora Revista dos Tribunais, 1984.

EISENMANN, Charles. Cours de Droit Administratif, t.I. Paris: LGDJ, 1982 O direito administrativo e o princípio da legalidade. In: Revista de Direito Administrativo, Rio de Janeiro: Renovar, v. 56, abril-junho, 1959.

FERRAZ, Anna Cândida da Cunha. Conflito entre poderes. São Paulo: Editora Revista dos Tribunais, 1994.

FERRAZ JÚNIOR, Tércio Sampaio. Introdução ao estudo do direito. 2. ed. São Paulo: Atlas, 1994. 
FERREIRA FILHO, Manoel Gonçalves. Curso de Direito Constitucional. $28^{\mathrm{a}}$ ed. São Paulo: Editora Saraiva, 2002.

. Do Processo Legislativo. São Paulo: Saraiva, 1995.

Estado de Direito e Constituição. 2a ed. rev. e ampl. São Paulo: Saraiva, 1999

O Parlamentarismo. São Paulo: Saraiva, 1993.

FIGUEIREDO, Lúcia Valle. Curso de direito administrativo. $4^{\text {a }}$ ed. São Paulo: Malheiros Editores, 2000.

FRANCO, Afonso Arinos de Mello. Direito constitucional: teoria da constituição - as constituições do Brasil, $2^{\text {a }}$ ed. Rio de Janeiro: Editora Forense, 1981.

FRIEDRICH, Carl J. An introduction to political theory, tradução de Leonidas Xausa e Luiz Corção, Rio de Janeiro, Zahar Editores, 1970.

GARCÍA DE ENTERRIA, Eduardo e FERNÁNDEZ, Tomáz-Ramón. Curso de Direito Administrativo. Editora Revista dos Tribunais. São Paulo: 1991.

GIACOMONI, James. Orçamento público, 14ª ed., ampl., rev., at., São Paulo: Editora Atlas, 2008.

GRAU, Eros Roberto, A ordem econômica na Constituição de 1988, $3^{\mathrm{a}}$ ed. São Paulo: Malheiros Editores, , 1997.

HOBBES, Thomas. Leviatã. In: Os pensadores. $4^{\mathrm{a}}$ ed. Trad. João Paulo Monteiro e Maria Beatriz Nizza da Silva. São Paulo: Nova Cultural, 1988. v. 1.

HOUAISS, Antônio. Dicionário Houaiss da língua portuguesa. Rio de Janeiro: Objetiva, 2001.

JARDIM, Eduardo Marcial Ferreira. Manual de Direito Financeiro e Tributário. $6^{\mathrm{a}}$ ed. São Paulo: Saraiva, 2003.

JELLINECK, Georg - Teoria General del Estado, 2a ed. Trad. de Fernando De Los Rios. Buenos Aires: Editorial Albatros, 1954.

KANTOROWICZ, Ernst Hatwig. Os dois corpos do rei: um estudo sobre teologia política medieval. São Paulo: Companhia das Letras, 1998.

KELSEN, Hans. Teoria pura do direito. São Paulo: Martins Fontes, 2000. 
Teoria Geral do Direito e do Estado, tradução de Luís Carlos Borges, $1^{\text {a }}$ ed., $2^{\text {a }}$ tiragem, São Paulo: Martins Fontes, 2000.

LARENZ, Karl. Metodologia da ciência do direito; tradução de José Lamego. $3^{a}$ ed., Coimbra: Fundação Calouste Gulbenkian, 1997.

LOEWENSTEIN, Karl. Teoría de la constitución. 2 ed. Barcelona: Editora Ariel, 1976.

MACHADO JÚNIOR, J. Teixeira e REIS, Heraldo da Costa. A Lei 4.320 comentada. Rio de Janeiro: IBAM, 1995.

MAXIMILIANO, Carlos. Hermenêutica e aplicação do Direito, $11^{\text {a }}$ ed. Rio de Janeiro: Forense, 1991.

MEDAUAR, Odete. A processualidade no direito administrativo. São Paulo: Editora Revista dos Tribunais, 1993.

. O direito administrativo em Evolução. $2^{\mathrm{a}}$ ed. São Paulo: Editora Revista dos Tribunais, 2003.

Direito Administrativo Moderno. 10 a ed. São Paulo: Editora Revista dos Tribunais, 2006.

Controle parlamentar da administração, in Revista de Informação Legislativa. Brasília: Senado federal - Subsecretaria de Edições Técnicas, v. 27, n. 107, jul./set. 1999.

MEIRELLES, Hely Lopes. A Administração Pública e seus controles. in Revista Justitia, ano XXXIV, 3/ trimestre 1972, vol. 78 .

Direito Administrativo Brasileiro. $31^{\mathrm{a}}$ ed. revista e atualizada por Eurico de Andrade Azevedo, Délcio Balestro Aleixo e José Emmanuel Burle Filho. São Paulo: Malheiros Editores, 2005.

Direito Municipal Brasileiro. $12^{\mathrm{a}}$ ed. atualizada por Célia Marisa Prendes e Márcio Schneider Reis. São Paulo: Malheiros Editores, 2001.

MELlO, Celso Antonio Bandeira de. Apontamentos sobre agentes e órgãos públicos. São Paulo: Editora Revista dos Tribunais, 1981.

Controles do poder político. In: Revista Trimestral de Direito Público, v. 11. São Paulo: Malheiros, 1995.

Curso de direito administrativo. 14ª ed. São Paulo: Malheiros Editores, 2001. 
Discricionariedade e controle jurisdicional. São Paulo: Malheiros Editores: 1996.

MELLO, Oswaldo Aranha Bandeira de. Princípios Gerais de Direito Administrativo, v. 1, $2^{\mathrm{a}}$ ed., Rio de Janeiro: Editora Forense, 1979.

MENDES, Antônio Carlos. Introdução à Teoria das Inelegibilidades. São Paulo: Malheiros Editores 1994.

MORAES, Alexandre de. Constituição do Brasil interpretada e legislação constitucional, $2^{\mathrm{a}}$ ed. São Paulo: Editora Atlas, 2003.

MOSCA, Gaetano. História das doutrinas políticas desde a Antiguidade, Rio de Janeiro: Zahar Editores, 1958.

NIESS, Pedro Henrique Távora. Direitos Políticos: Condições de Elegibilidade e Inelegibilidades. São Paulo: Editora Saraiva, 1994.

OLIVEIRA, Régis Fernandes de, e HORVATH, Estevão. Manual de Direito Financeiro, $6^{\mathrm{a}}$ ed. Editora Revista dos Tribunais: São Paulo, 2003.

OSÓRIO, Fábio Medina. Improbidade Administrativa. Porto Alegre: Editora Síntese, 1998.

PERES, Jefferson. Parecer n $n^{\circ}$ /99-CN da Comissão Mista de Planos, Orçamentos Públicos e Fiscalização sobre as "Contas do Governo Federal referentes ao exercício de 1996”. In: Diário da Câmara dos Deputados, edição de 04/09/1999.

POGGI, Gianfranco. A evolução do Estado Moderno: uma introdução sociológica. Trad. Álvaro Cabral. Rio de Janeiro: Zahar Editores, 1981.

RAMOS, Elival da Silva. Representação e democracia. In "Cadernos de direito constitucional e eleitoral”, São Paulo: Imprensa Oficial do Estado S.A. Imesp, n. 9, 1990.

Do ato administrativo complexo no direito brasileiro e italiano. In: Revista da ProcuradoriaGeral do Estado de São Paulo n 32, São Paulo: dez. 1989.

REALE, Miguel. Teoria do Direito e do Estado, 5 ed. Revista, 2a tiragem, São Paulo: Saraiva, 2003. Lições Preliminares de Direito, 29ª ed., São Paulo: Editora Saraiva, 2003.

RIBEIRO, Fávila. Direito Eleitoral. Rio de Janeiro: Editora Forense, 1996. 
RIGOLIN, Ivan Barbosa. e NUNES, Moacyr de Araújo. Emendas parlamentares ao projeto de orçamento. In: Boletim de Direito Municipal. São Paulo: Editora NDJ, fev/2007.

ROLLO, Alberto e BRAGA, Enir. Inelegibilidade à Luz da Jurisprudência. São Paulo: Fiuza Editores, 1995.

ROUSSEAU, Jean-Jacques. Do contrato social. Os pensadores. $4^{\mathrm{a}}$ ed. Trad. Lourdes Santos Machado. São Paulo: Nova Cultural, 1987.

SAMPAIO, Nelson de Souza. O Processo Legislativo. Belo Horizonte: Editora Del Rey, 1996.

SEABRA FAGUNDES, Miguel. O controle dos atos administrativos pelo Poder Judiciário. $6^{\mathrm{a}}$ ed. São Paulo: Saraiva, 1984.

SIÉYES, Emmanuel Joseph. A constituinte burguesa. $4^{\mathrm{a}}$ ed. Organização e introdução de Aurélio Wander Bastos. Tradução Norma Azeredo, Rio de Janeiro: Lúmen Júris, 2001.

SILVA, José Afonso da. Aplicabilidade das normas constitucionais. $6^{\text {a }}$ ed., $2^{\text {a }}$ tiragem, São Paulo: Malheiros, 2003.

. Comentário Contextual à Constituição, $4^{\mathrm{a}}$ ed., São Paulo: Malheiros, 2007

Curso de Direito Constitucional Positivo., 25a ed., São Paulo: Malheiros, 2005.

Orçamento-programa no Brasil, São Paulo: Revista dos Tribunais, 1972.

STRAYER, Joseph R. On the medieval origins of the modern state. Lisboa: Gradiva, 1969.

TAVARES, André Ramos. Direito constitucional econômico. São Paulo: Editora Método, 2003.

TORRES, Ricardo Lobo. Constituição e orçamento. In: Tratado de Direito Constitucional, Financeiro e Tributário, v. 5, $3^{\mathrm{a}}$ ed. Rio de Janeiro: Renovar, 2003.

Curso de Direito Financeiro e Tributário. $8^{\mathrm{a}}$ ed. Rio de Janeiro: Renovar, 2001. O Orçamento na Constituição. Rio de Janeiro: Renovar, 1995.

WEBER, Max. Economia e sociedade: fundamentos da sociologia compreensiva. Wirtschaft und Gesellschaft: Grundriss der verstehenden Soziologie. Tradução de Regis Barbosa e Karen Elsabe Barbosa. Editora Universidade de Brasília: São Paulo: Imprensa Oficial do Estado de São Paulo. 
WOLKMER, Antonio Carlos. Elementos para uma crítica do Estado. Porto Alegre: Sérgio Antonio Fabris Editor, 1990.

ZANOBINI, Guido. "L'attività amministrativa e la legge". In: Scritti vari di diritto pubblico, Milão, Dott. A. Giuffrè-Editore, 1955. 